\title{
Estudo da adição de albumina e da temperatura de secagem nas características de polpa de tomate em pó
}

\section{Study of the albumin addition and drying temperature on the characteristics of tomato pulp powder}

\author{
Regiane Victória de Barros Fernandes ${ }^{1 *}$; Fabiana Queiroz ${ }^{2}$; Diego Alvarenga \\ Botrel $^{3}$; Vitangela Vieira Rocha ${ }^{1}$; Vívian Raquel de Souza ${ }^{1}$; Carla Ferreira de Lima ${ }^{1}$
}

\section{Resumo}

Este trabalho foi realizado com o objetivo de avaliar a influência da adição de agente espumante e da temperatura de secagem nas características dos pós produzidos a partir de polpa de tomate in natura. Foi avaliada a influência destes tratamentos nas variáveis $\mathrm{pH}$, acidez titulável, ácido ascórbico, densidade compactada, solubilidade e higroscopicidade dos pós produzidos nas temperaturas de secagem de $60^{\circ} \mathrm{C}$ e $80^{\circ} \mathrm{C}$, adicionados ou não de albumina. Verificou-se a ocorrência de maiores valores de acidez e menores valores de $\mathrm{pH}$ para os tratamentos adicionados de albumina em ambas temperaturas. A concentração de ácido ascórbico da polpa foi reduzida significativamente $(p<0,05)$ com o aumento da temperatura de secagem em relação à polpa in natura. Verificou-se ainda que a aplicação de albumina contribuiu para uma redução no teor de ácido ascórbico. Por outro lado, a adição de albumina, com consequente formação de espuma na polpa de tomate, favoreceu a produção de materiais em pó com menor densidade quando comparados aos tratamentos controle sem adição de albumina. A presença de albumina causou ainda redução significativa $(p<0,05)$ na higroscopicidade dos materiais em pó. A solubilidade foi aumentada com adição do agente espumante onde foi verificada diferença significativa $(p<0,05)$ entre os tratamentos com e sem adição de albumina em ambas as temperaturas.

Palavras-chave: Polpa de tomate, secagem, camada em espuma, propriedades de reconstituição

\begin{abstract}
The aim of this work was to evaluate the influence of the addition of foaming agent and drying temperature on the powders characteristics produced using tomato pulp. The influence of the treatments on the $\mathrm{pH}$, titratable acidity, ascorbic acid, tapped density, solubility and hygroscopicity of the powders produced at drying temperatures of $60^{\circ} \mathrm{C}$ and $80^{\circ} \mathrm{C}$, with addition of albumin and with no albumin were evaluated. Higher values of acidity and lower values of $\mathrm{pH}$ were observed for the treatments added with albumin in both temperatures were verified. The ascorbic acid content in the pulp was significant $(\mathrm{p}<0.05)$ decreased with the increasing oh the drying temperature compared to the pulp in natura. The application of albumin also contributes to a decrease in the ascorbic acid content. By the other hand, the albumin addition, with consequent foaming formation in the tomato pulp, favored the production of powder materials with lower density when compared to the control treatments without albumin. The presence of albumin also caused a significant reduction $(\mathrm{p}<0.05)$ in the powder materials hygroscopicity. The powders solubility was increased with addition of the foaming agent where significant difference $(\mathrm{p}<0.05)$ among the treatments with and without albumin in both temperatures were observed.
\end{abstract}

Key words: Tomato pulp, drying, foam mat, reconstitution properties

\footnotetext{
1 Pesquisadores da Universidade Federal de Viçosa, UFV, Campus de Rio Paranaíba, Rio Paranaíba, MG. E-mail: regiane. fernandes@ufv.br; vitangela@ufv.br; vivian.souza@ufv.br; carla_patos@hotmail.com

2 Prof $f^{a}$ do Departamento de Ciência dos Alimentos, Universidade Federal de Lavras, UFLA, Lavras, MG. E-mail: fqueiroz@dca. ufla.br

3 Prof. do Departamento de Ciência dos Alimentos, Universidade Federal de Lavras, UFLA, Lavras, MG. E-mail: diego.botrel@ dca.ufla.br

* Autor para correspondência
} 


\section{Introdução}

Os produtos de origem vegetal são como importantes fontes de componentes como vitaminas, sais minerais, carboidratos, fibras e outros nutrientes (FILGUEIRA, 2003). O tomate (Lycopersicon esculentum Mill) é um dos produtos vegetais mais versáteis e amplamente consumido no mundo (CRUZ; BRAGA; GRANDI, 2012). Classificado como um fruto climaterico, está entre os produtos agrícolas com maiores perdas, em razão da sua elevada perecibilidade (CASA; EVANGELISTA, 2009).

No Brasil, embora ocorra uma grande disponibilidade de produtos hortícolas acessíveis à uma crescente parcela da população, observam-se níveis inaceitáveis de perdas destes produtos devido a técnicas inadequadas adotadas desde a colheita até $\mathrm{o}$ armazenamento. $\mathrm{O}$ processamento de hortaliças pode contribuir com a redução de desperdícios, além de possibilitar maior praticidade e economia de tempo no preparo diário de alimentos, cada vez mais necessários no mundo moderno (ALVES et al., 2010). O excedente de produção, gerado na época de safra e a alta perecibilidade dos alimentos, associados à ausência e ou deficiência de técnicas adequadas de manuseio, transporte e armazenamento, têm gerado grandes perdas, que podem ser reduzidas pelo processamento (CORREIA; FARAONI; PINHEIRO-SANT’ANA, 2008).

A secagem é uma importante tecnologia póscolheita que apresenta diversas vantagens, dentre as quais a facilidade na conservação do produto; a proteção contra reações de degradação; a redução do peso; a economia de energia por não necessitar de refrigeração; e a disponibilidade do produto durante qualquer época do ano. É também um dos processos mais utilizados para melhorar a estabilidade dos alimentos, uma vez que diminui consideravelmente a atividade de água, reduz a atividade microbiológica e minimiza alterações físicas e químicas durante o armazenamento (MAYOR; SERENO, 2004).

Muitas pesquisas têm sido realizadas para avaliar as características de reidratação de alimentos desidratados e de qualidade do produto final através do estudo de variáveis do processo tais como tempo de secagem, temperatura do ar de secagem no secador, tipo de material a ser seco, tipo de secador e método de pré-tratamento da amostra (CUNNINGHAM et al., 2008). Para a secagem de vegetais, a literatura retrata a temperatura de $80{ }^{\circ} \mathrm{C}$ como limite para a desidratação destes alimentos e, a temperatura de $60{ }^{\circ} \mathrm{C}$, como sendo a mais comumente utilizada para não comprometer a qualidade do produto final. Estes limites são determinados em função da sensibilidade dos componentes (MARTINAZZO et al., 2010) e em função das propriedades de reconstituição dos produtos desidratados, que estão associadas com a facilidade de dispersão do produto seco numa solução aquosa e incluem parâmetros como densidade, higroscopicidade e solubilidade (FERNANDES; BORGES; BOTREL, 2013). No estudo de Coelho e Pinto (2011), a reidratação do tomate seco foi mais eficiente e o produto apresentou maior teor de licopeno quando o produto foi seco a temperatura de $60^{\circ} \mathrm{C}$ do que às temperaturas de $70^{\circ} \mathrm{C}$ e $80^{\circ} \mathrm{C}$, além disso foi maior naquela condição.

A secagem por espuma é um processo no qual um líquido é agitado para incorporação de ar e para a formação de uma espuma estável, sendo então desidratado (KUDRA; MUJUMDAR, 2001). As principais vantagens método são a possibilidade de utilização de baixas temperaturas e curtos tempos de secagem, quando comparados à secagem de materiais não espumados em um mesmo tipo de secador, o que contribui para reduzir a degradação térmica de produtos secos quando comparados à secagem convectiva convencional $\mathrm{O}$ menor tempo de secagem é resultado da ocorrência de uma maior superfície de contato exposta ao ar de secagem, e também de particularidades na transferência de calor e massa em materiais espumados (RATTI; KUDRA, 2006). Este tipo de secagem permite o processamento de biomateriais difíceis de secar tais como pasta de tomate, assim como a produção de materiais que se reidratam facilmente e retêm 
alguns indicadores de qualidade como cor, aroma, textura e valores nutricionais. .

Diversos agentes espumantes, como a proteína isolada de soja (SANKAT; CASTAIGNE, 2004) e a albumina de ovo desidratado (GARCIA; LEAL; ROLZ, 1988) podem ser utilizados para produzir alimentos desidratados pelo processo de espuma. As espumas devem manter a estrutura aberta durante a secagem, mas sem que ocorra a sua quebra, o que poderia ocasionar em um aumento do tempo de secagem e um produto com qualidade prejudicada. Kadam, Wilson e Manisha (2012) estudaram a influência da secagem por espuma na qualidade de polpa de tomate utilizando carboximetilcelulose, albumina de ovo e leite como agentes espumantes e estabilizantes, e concluíram que esta tecnologia é promissora na conservação de tomates na forma em pó sem perdas consideráveis de nutrientes. No estudo da secagem por espuma de banana, Thuwapanichayanan, Prachayawarakorn e Soponronnarit (2012) encontraram melhores propriedades de formação da espuma para os tratamentos adicionados dos agentes espumantes albumina e concentrado proteico de soro quando comparados ao isolado proteico de soja.

A pesquisa e o desenvolvimento de um processo de desidratação que resulte em um produto de qualidade, com alto valor agregado, são de interesse. Dentro deste contexto, os objetivos deste trabalho foram avaliar a secagem de polpa de tomate em duas temperaturas $\left(60^{\circ} \mathrm{C}\right.$ e $\left.80^{\circ} \mathrm{C}\right)$, submetido a um pré-tratamento com adição de albumina para formação de espuma, e determinar as características físico-químicas dos pós produzidos em comparação à secagem da polpa in natura.

\section{Material e Métodos}

Foram utilizados tomates da variedade Saladete adquiridos no comércio local da cidade de Carmo do Paranaíba-MG com valor médio de $4,0{ }^{\circ}$ Brix. Todas as amostras utilizadas no experimento pertenciam à mesma safra e ao mesmo lote. Os tomates foram lavados em água corrente e sanitizados com solução de hipoclorito de sódio (Sumaveg®) a $200 \mathrm{mg} / \mathrm{kg}$. Os tomates foram fatiados em quatro pedaços e submetidos à trituração, durante $30 \mathrm{~s}$, com auxílio de liquidificador doméstico. Após este processo, a polpa foi filtrada utilizando-se peneira de nylon para a retirada das sementes e casca.

As formulações foram preparadas pesandose a polpa de tomate e a albumina (Salto's ${ }^{\circledR}$ ). A concentração de albumina utilizada foi de 4,5 g/100 g de mistura (4,5 \% de albumina em relação à massa total da solução) e os ingredientes foram homogeneizados em liquidificador por 30 s. A incorporação de ar foi feita com auxílio de uma batedeira (Arno Ciranda Chrome Automatic $($ ) durante 4,5 min em rotação máxima, de acordo com valores otimizados em estudos prévios (FERNANDES et al., 2013a). Para a incorporação do ar, realizada à temperatura ambiente, foi utilizada apenas uma haste da batedeira e empregou-se um béquer de plástico de $1000 \mathrm{~mL}$.

Os tratamentos aplicados, polpa controle (sem adição de albumina) e polpa adicionada de 4,5 $\%$ de albumina, foram levados à secagem nas temperaturas de $60^{\circ} \mathrm{C}$ e $80^{\circ} \mathrm{C}$ em um secador de bandejas com circulação e renovação de ar forçada no sentido horizontal (Marqlabor ${ }^{\circledR}$, modelo ES/ CF 216) com velocidade mantida em $1,5 \mathrm{~m} / \mathrm{s}$. O experimento foi conduzido em três repetições. $\mathrm{O}$ tempo de secagem utilizado foi o necessário para que a amostra atingisse a massa constante com intervalo para pesagem das amostras de $30 \mathrm{~min}$. Para todas as secagens, a espuma foi uniformemente depositada em bandejas planas circulares de alumínio (bandejas circulares, planas, medindo $40 \mathrm{~cm}$ de diâmetro e $0,5 \mathrm{~cm}$ de altura), sendo estas preenchidas com uma massa de espuma, de modo a ocupar toda a superfície da bandeja para secagem.

Os materiais em pó foram obtidos pela raspagem das bandejas contendo a polpa de tomate seca, sendo submetidos à trituração em liquidificador doméstico, com agitação máxima por $5 \mathrm{~s}$. A reconstituição 
destes materiais em água destilada foi realizada até que se obtivesse o valor de $4{ }^{\circ}$ Brix, valor de sólidos solúveis similar ao da polpa de tomate empregada nos experimentos.

Para a determinação do $\mathrm{pH}$ da polpa de tomate e dos tratamentos em pó reconstituídos, foi utilizado medidor de $\mathrm{pH}$ digital portátil MS Tecnopon Instrumentos mPA-210P. A acidez total titulável foi determinada utilizando-se $\mathrm{NaOH} 0,1 \mathrm{~N}$. O ponto de viragem foi determinado pela medida do $\mathrm{pH}(8,10$ $\pm 0,02)$, conforme metodologia recomendada por Adolfo Lutz (2005) para amostras coloridas. Os resultados foram expressos em \% de ácido cítrico (g de ácido cítrico por $100 \mathrm{~g}$ de polpa de tomate in natura ou reconstituída). O teor de ácido ascórbico das amostras foi estimado utilizando o método titulométrico usando o 2,6-diclorofenolindofenol, segundo metodologia descrita por Adolfo Lutz (2005). O resultado foi expresso em g de ácido ascórbico por $100 \mathrm{~g}$ de polpa de tomate in natura ou reconstituída, considerando o teor de sólidos da polpa para o último caso.

Para a determinação da densidade compactada, $2 \mathrm{~g}$ do pó foram colocadas em uma proveta de 10 $\mathrm{mL}$. O cilindro contendo o pó foi batido levemente em superfície plana até volume constante. O volume final foi anotado e a densidade compactada foi calculada dividindo-se o peso da amostra pelo volume (BHANDARI et al., 1992). A solubilidade foi determinada segundo o método descrito por Wang et al. (2000). Foram pesados 2,5 g de amostra em um tubo de centrífuga, adicionados de $30 \mathrm{~mL}$ de água, sendo a mistura agitada por 30 minutos com auxílio de agitador magnético, e em seguida a solução foi centrifugada (centrífuga Nova Técnica ${ }^{\circledR}$, modelo NT 820) a $2.300 \mathrm{rpm}$ por $10 \mathrm{~min}$. O sobrenadante foi transferido para uma placa de petri, seco em estufa a $100^{\circ} \mathrm{C}$ por $3 \mathrm{~h}$ para a determinação dos sólidos solúveis em água. O resultado foi expresso em g de amostra solúvel em $100 \mathrm{~mL}$ da solução. Para a medida de higroscopicidade, amostras (2,0 g) de cada tratamento foram colocadas em placas de petri a $25^{\circ} \mathrm{C}$ em dessecadores de vidro contendo solução saturada de $\mathrm{Na}_{2} \mathrm{SO}_{4}$ (umidade relativa de $81 \%$ ). Depois de uma semana, as amostras foram pesadas, e a higroscopicidade foi expressa como $\mathrm{g}$ de água adsorvida/100 g de sólido seco (CAI; CORKE, 2000).

O experimento foi conduzido em delineamento inteiramente casualizado em esquema fatorial. Foi realizada análise de variância (ANOVA), e teste de médias Tukey em nível de $5 \%$ de probabilidade, para verificar a influência dos fatores temperatura $\left(60{ }^{\circ} \mathrm{C}\right.$ e $\left.80{ }^{\circ} \mathrm{C}\right)$ e albumina $(0$ e $4,5 \mathrm{~g} / 100 \mathrm{~g}$ de mistura) e suas interações nas variáveis resposta: $\mathrm{pH}$, acidez titulável, ácido ascórbico, densidade compactada, solubilidade e higroscopicidade.

\section{Resultados e Discussão}

Os resultados mostraram que a formação de espuma com o uso de albumina reduziu o tempo para que se atingisse a umidade de equilíbrio durante a secagem. Este fato foi observado nas duas temperaturas estudadas (Figura 1). Os tempos necessários para se atingir a umidade de equilíbrio na temperatura de $60{ }^{\circ} \mathrm{C}$ foram de 400 minutos e 590 minutos para os tratamentos com espuma e sem formação de espuma, respectivamente. Já para a temperatura de secagem de $80{ }^{\circ} \mathrm{C}$ os tempos foram menores quando comparados à temperatura de 60 ${ }^{\circ} \mathrm{C}$ sendo de 180 minutos e 240 minutos para os tratamentos com espuma e sem formação de espuma, respectivamente. Em geral, a secagem de materiais espumados é mais rápida quando comparado com aqueles em que não ocorre o processo de espuma. $\mathrm{O}$ efeito da temperatura na secagem foi observado, visto que a maior temperatura contribuiu para o menor tempo de secagem. Silva et al. (2008) verificaram também, através curvas de secagem em camada de espuma da polpa de tamarindo, que um acréscimo na temperatura favoreceu a diminuição do tempo de secagem. 
Figura 1. Curvas de secagem em função do tempo da polpa de tomate nos diferentes tratamentos.

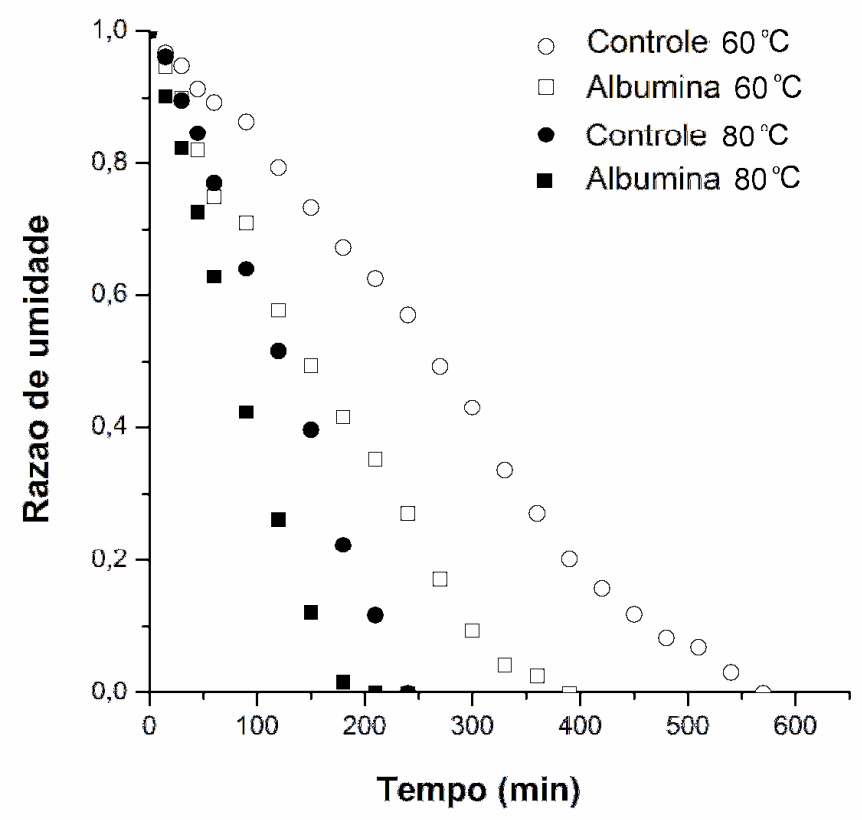

Fonte: Elaboração dos autores.

Os valores do $\mathrm{pH}$, acidez total titulável e concentração de ácido ascórbico encontrados para a polpa de tomate in natura podem ser observados na Tabela 1. Verificou-se que, entre os tratamentos reconstituídos com adição de albumina, o pH não apresentou diferença significativa $(p>0,05)$ em ambas as temperaturas estudadas (Tabela 2). A presença de albumina contribuiu para o aumento no valor de $\mathrm{pH}$ e redução no valor da acidez quando comparados aos tratamentos controle, provavelmente em função de sua natureza química (Figura 2). Este fato mostra que a adição deste agente espumante pode provocar ligeiras alterações no $\mathrm{pH}$ do produto. $\mathrm{O} \mathrm{pH}$ da polpa de tomate in natura
$(4,16)$ foi similar aos tratamentos reconstituídos sem adição de albumina a $60^{\circ} \mathrm{C}$ e $80^{\circ} \mathrm{C}$ (não diferentes entre si). $\mathrm{O}$ pH representa o inverso da concentração de íons hidrogênio $\left(\mathrm{H}^{+}\right)$em um dado material. $\mathrm{O}$ valor do $\mathrm{pH}$ interfere de maneira significativa no crescimento de microrganismos e na seleção da flora (CHITARRA; CHITARRA, 2005). No estudo da desidratação da polpa de tamarindo pelo método de camada de espuma, Silva et al. (2008) verificaram que a adição do agente promotor de espuma, um composto proteico à base de albumina, reduziu a acidez titulável dos produtos secos obtidos, comportamento este que, segundo os autores, pode estar relacionado à alcalinidade do agente.

Tabela 1. Valores de pH, acidez titulável e ácido ascórbico da polpa de tomate in natura.

\begin{tabular}{cc}
\hline Variável & Média e desvio padrão \\
\hline $\mathrm{pH}$ & $4,16 \pm 0,02$ \\
\hline Acidez titulável $(\mathrm{g} / 100 \mathrm{~g})$ & $0,34 \pm 0,02$ \\
\hline Ácido ascórbico $(\mathrm{g} / 100 \mathrm{~g})$ & $66,67 \pm 0,01$ \\
\hline
\end{tabular}

Fonte: Elaboração dos autores. 
Figura 2. Valores médios de $\mathrm{pH}$ e acidez titulável (expressa em \% de ácido cítrico), para os tratamentos estudados.
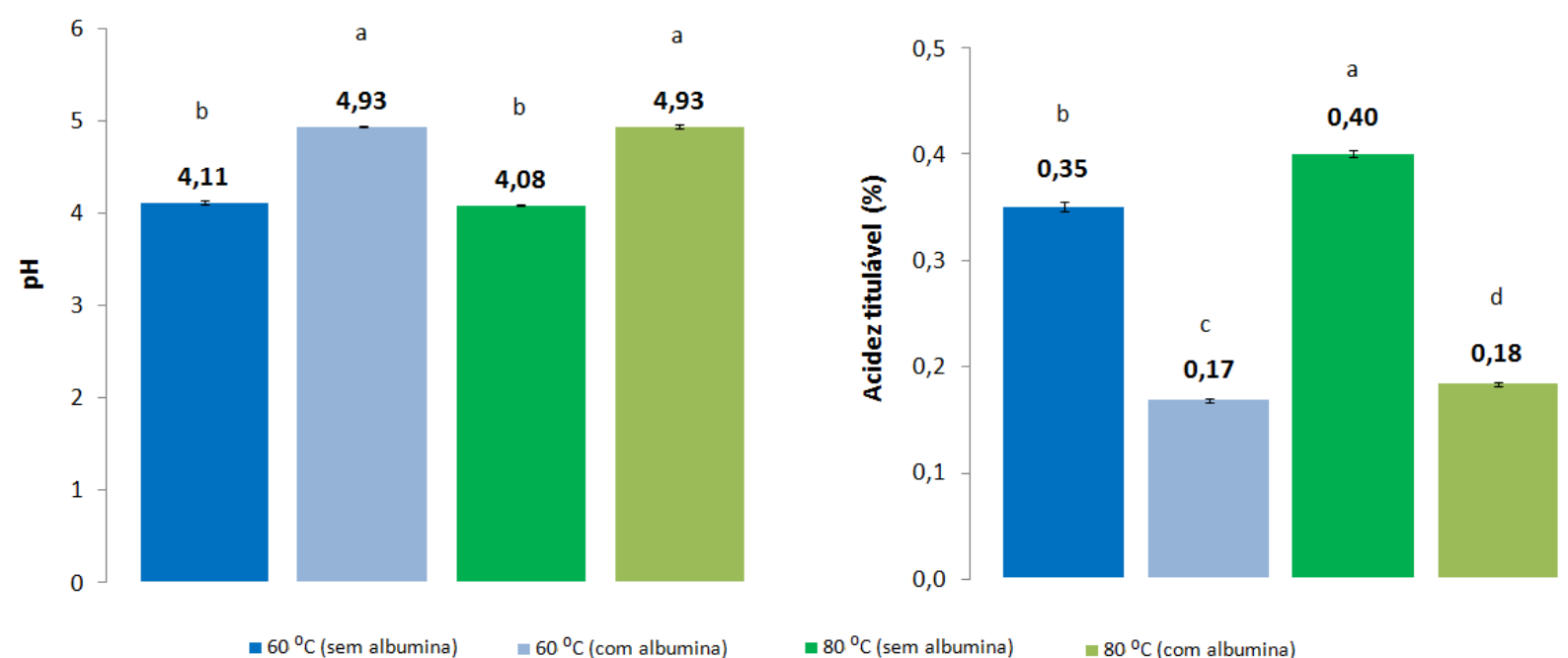

${ }^{\mathrm{a}-\mathrm{c}}$ médias médias seguidas por letras diferentes na mesma coluna diferem entre $\mathrm{si}(\mathrm{p}<0,05)$.

Fonte: Elaboração dos autores.

Para o teor de ácido ascórbico (vitamina C), houve diferença significativa para os fatores albumina e temperatura estudados em nível de $5 \%$ de probabilidade (Tabela 2). A elevação da temperatura provocou uma diminuição no teor de ácido ascórbico $(p<0,05)$ (Figura 3), nos tratamentos com e sem albumina. A concentração de ácido ascórbico da polpa in natura $(66,7 \mathrm{mg} / 100 \mathrm{~g})$ foi reduzida significativamente $(\mathrm{p}<0,05)$ com a aplicação do tratamento térmico (desidratação). A redução de vitamina $\mathrm{C}$, em relação à polpa in natura, para as temperaturas de $60{ }^{\circ} \mathrm{C}$ e $80{ }^{\circ} \mathrm{C}$, respectivamente, chegou a valores de $63 \%$ e $75 \%$ para a secagem sem a albumina, e a valores de $73 \%$ e $82 \%$ com o uso de albumina. A aplicação de albumina provocou redução no teor de ácido ascórbico no produto final. O uso de albumina, por aumentar a superfície de contanto do material com o ar, na forma de espuma, pode ter contribuído para uma maior exposição dos constituintes da polpa, incluindo o ácido ascórbico, aos efeitos da luz e do oxigênio, reduzindo o seu teor quando comparado ao processo sem a adição de albumina em uma mesma temperatura. Os processos de oxidação que ocorrem em produtos submetidos à secagem podem ser controlados por diversos fatores. Além da temperatura e do teor de umidade, a exposição à luz e ao oxigênio exercem grande influência e seus efeitos precisam ser melhor investigados (GIOVANELLI; PARADISO, 2002). A redução na concentração de ácido ascórbico durante processos de secagem ocorre também devido à natureza sensível ao calor desta substância (KADAM; WILSON; MANISHA, 2012). Declínios similares no conteúdo de ácido ascórbico foram relatados por outros autores em batata (MEHTA et al., 2007), repolho (KADAM; LATA; PANDEY, 2005) e cebola (KADAM; NANGARE; OBEROI, 2009) quando submetidos a tratamentos térmicos. 
Tabela 2. Resumo do quadro de ANOVA para as variáveis estudadas.

\begin{tabular}{cccccccccccccc}
\hline Variáveis & \multicolumn{2}{c}{$\mathbf{p H}$} & \multicolumn{4}{c}{ Acidez titulável } & \multicolumn{2}{c}{$\begin{array}{c}\text { Ácido } \\
\text { ascórbico }\end{array}$} & \multicolumn{2}{c}{$\begin{array}{c}\text { Densidade } \\
\text { compactada }\end{array}$} & Higroscopicidade & Solubilidade \\
\hline FV & F & p-valor & F & p-valor & F & p-valor & F & p-valor & F & p-valor & F & p-valor \\
\hline Albumina (A) & 8366,7 & 0,000 & 11820,31 & 0,000 & 50,769 & 0,000 & 8967,1 & 0,000 & 11211,3 & 0,000 & 454,62 & 0,000 \\
Temperatura (T) & 2,7 & 0,139 & 315,08 & 0,000 & 77,150 & 0,000 & 4042,5 & 0,000 & 1,8 & 0,213 & 1,05 & 0,335 \\
A versus T & 2,7 & 0,139 & 88,92 & 0,000 & 1,821 & 0,214 & 1979,0 & 0,000 & 1,2 & 0,298 & 11,46 & 0,010 \\
\hline
\end{tabular}

$\operatorname{Ftab}(0,05)=5,32$.

Fonte: Elaboração dos autores.

Figura 3. Valores médios de ácido ascórbico para os tratamentos estudados.

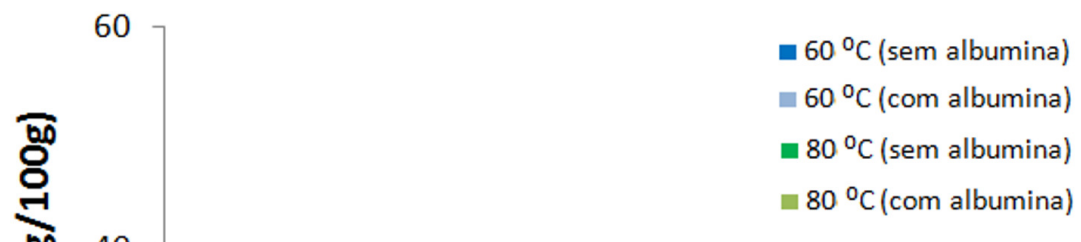

a

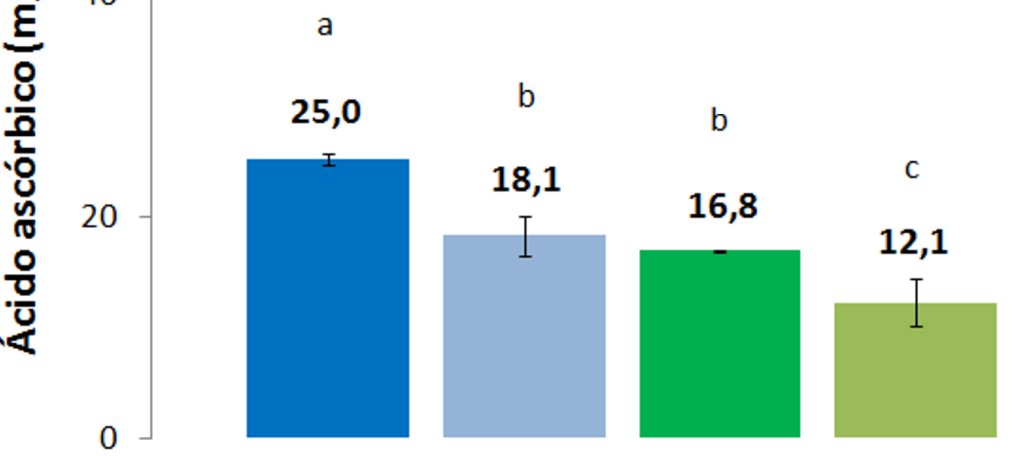

${ }^{\mathrm{a}-\mathrm{c}}$ médias médias seguidas por letras diferentes na mesma coluna diferem entre si $(\mathrm{p}<0,05)$.

Fonte: Elaboração dos autores.

O aspecto visual dos pós produzidos com e sem adição de albumina é mostrado na Figura 4. Os pós de polpa de tomate produzidos sem adição de albumina apresentaram uma cor vermelha escura e características gomosas. Por outro lado, os pós com adição de albumina apresentaram cor alaranjada clara, influenciada pela adição de albumina sem ocorrência visual de agregação (características vítreas) e de escoamento livre. A transição vítrea (Tg) é a transição de fase de materiais amorfos durante sua passagem gradual de um estado gomoso (alta mobilidade de água) para um estado vítreo relativamente rígido (baixa mobilidade de água) (ROOS, 2002; GENIN; RENÉ, 1995). A Tg é de extrema importância para materiais em pó, pois caso a temperatura ambiente exceda a $\mathrm{Tg}$, mudanças nas propriedades físicas podem ocorrer em função do estabelecimento do estado gomoso, tais como pegajosidade, cristalização e colapso da estrutura (NETTO; DESOBRY; LABUZA, 1998). $\mathrm{O}$ alto conteúdo de carboidratos de baixo peso molecular e ácidos orgânicos na polpa de tomate diminuem a $\mathrm{Tg}$ abaixo da temperatura do produto. Este fato leva à existência do estado gomoso de um material amorfo, que é responsável pela coesão ou adesão entre partículas (TRUONG; BHANDARI; HOWES, 2005). A formação de aglomerados pode levar a uma redução da dispersibilidade do produto 
desidratado em água (FERNANDES; BORGES, BOTREL, 2013). A alta Tg das proteínas fornecem boa estabilidade ao pó seco. $\mathrm{O}$ alto peso molecular de polímeros alimentícios tais como carboidratos e proteínas possuem alta $\mathrm{Tg}$ e são considerados estáveis. A adição destes agentes na solução é importante nos processos de secagem.

A densidade compactada dos pós obtidos foi influenciada significativamente pelos fatores albumina e temperatura. Verificou-se ainda interação significativa em nível de $5 \%$ de probabilidade (Tabela 2). A variação da densidade entre os tratamentos com e sem adição de albumina é consequência da estrutura porosa da espuma formada durante o processo de secagem. Adensidade é um fator importante relacionado ao transporte, embalagem e comercialização dos pós, assim, este valor pode ser útil em termos de peso e quantidade de material que vai se acomodar dentro de um recipiente (FINNEY; BUFFO; REINECCIUS, 2002). A maior quantidade de ar incorporada durante o processo de secagem por espuma resulta em menores valores de densidades para estes tipos de produtos secos (FALADE; ADEYANJU; UZOPETERS, 2003; THUWAPANICHAYANAN; PRACHAYAWARAKORN; SOPONRONNARIT, 2012) devido principalmente à estrutura porosa obtida. Vários produtos são utilizados para auxiliar na formação de espuma e na estabilização das emulsões formadas tais como proteínas e monoglicerídeos, sendo a albumina uma eficaz proteína formadora de espuma e que tem sido utilizada em vários estudos de secagem (FALADE; ADEYANJU; UZO-PETERS, 2003; FERNANDES et al., 2013a). Os resultados mencionados podem ser observados na Figura 5.

Figura 4. Aspectos visuais dos pós de polpa de tomate produzidos sem adição de albumina (esquerda) e com adição de albumina (direita).
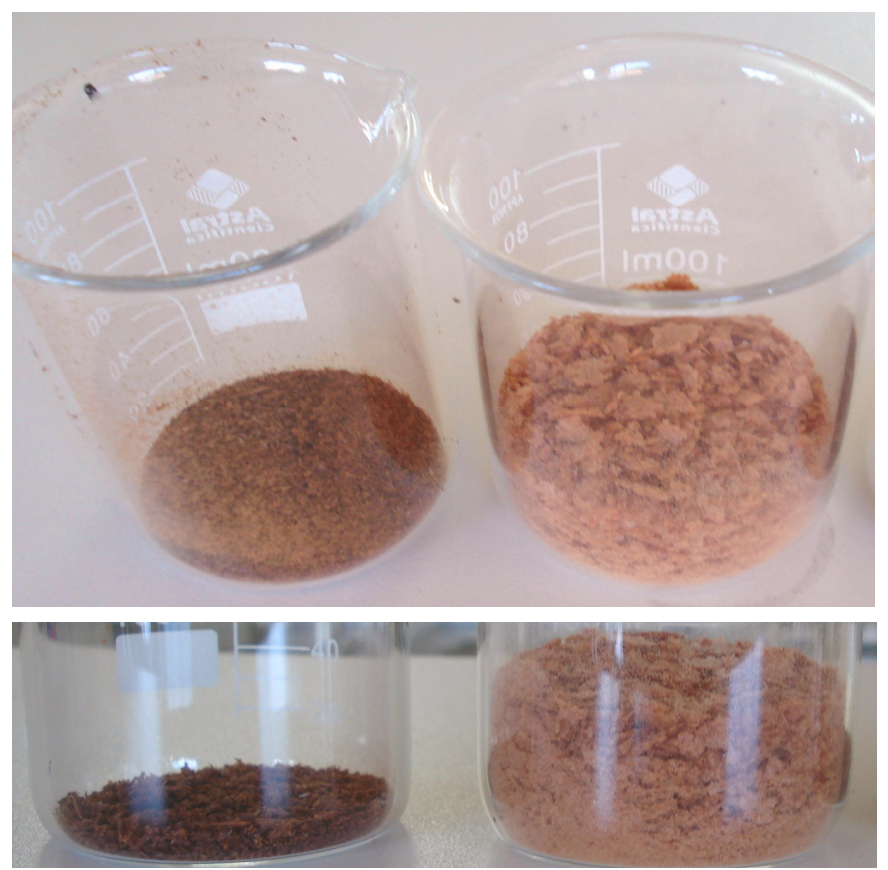

Fonte: Elaboração dos autores. 
Figura 5. Valores médios de densidade compactada para os tratamentos estudados.

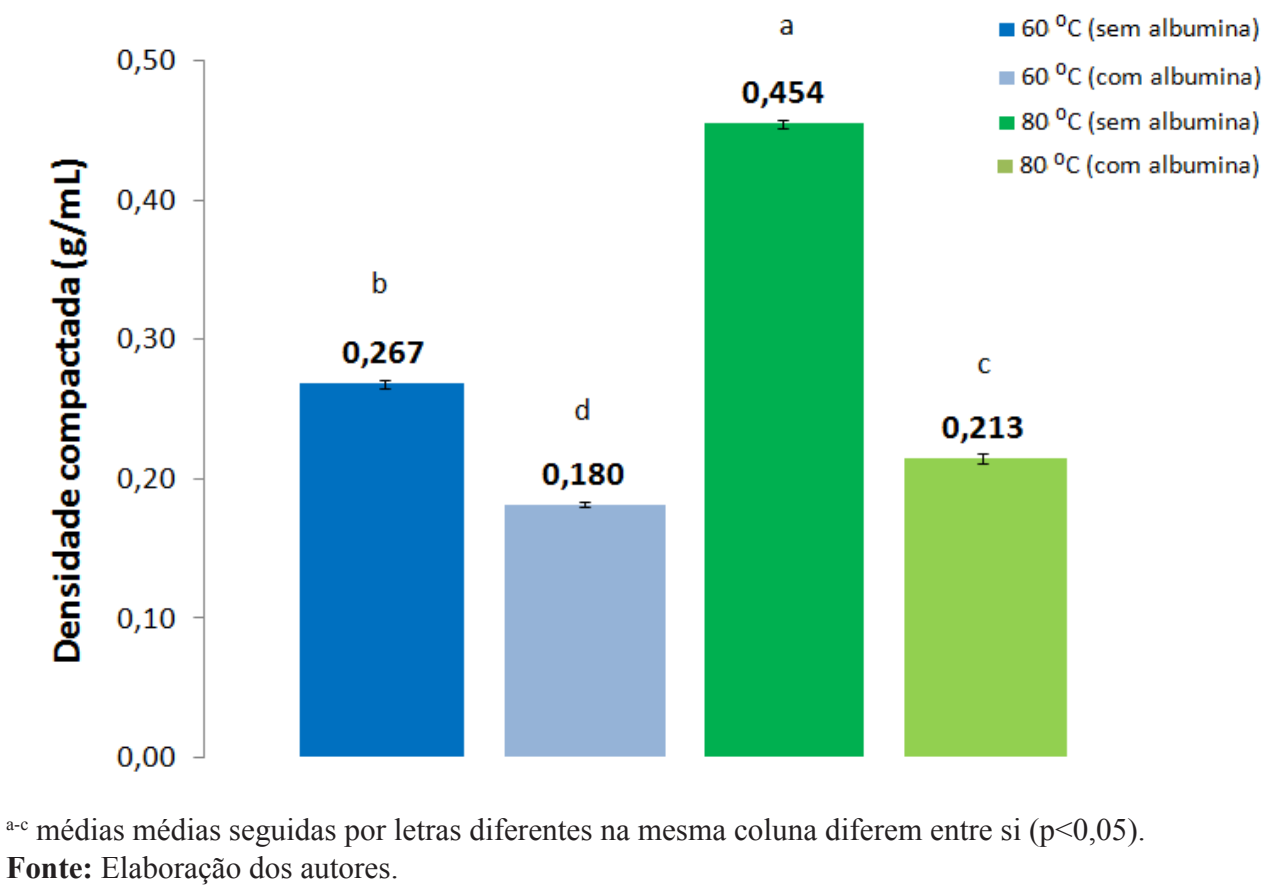

Ahigroscopicidade dos materiais está relacionada à capacidade do pó em absorver umidade do ambiente. Este fato está relacionado à estabilidade do produto e sua consequente vida de prateleira (FERNANDES et al., 2013b). Para uma melhor conservação e estabilidade dos pós são desejáveis menores valores de absorção de água (BOTREL et al., 2012), contribuindo também para melhores propriedades de reconstituição, evitando a formação de aglomerados e não influenciando no abaixamento da $\mathrm{Tg}$. Com o aumento da umidade, a Tg é reduzida e as características dos materiais em pó podem ser alteradas. Maiores Tg produzem partículas mais estáveis durante o processamento e, principalmente, estocagem (BERISTAIN; AZUARA; VERNONCARTER, 2002; BHANDARI; HARTEL, 2005). A avaliação estatística dos dados de higroscopicidade mostrou haver diferença significativa apenas para o fator albumina, em nível de $5 \%$ de probabilidade (Tabela 2). Os tratamentos contendo albumina resultaram em pós com menores valores de higroscopicidade, próximos a $41 \mathrm{~g}$ de água adsorvida/100 $\mathrm{g}$ de sólido seco para as temperaturas de $60{ }^{\circ} \mathrm{C}$ e $80{ }^{\circ} \mathrm{C}$ (Figura 6). A adição de albumina na formulação reduziu a influência dos açúcares e ácidos orgânicos da polpa de tomate em pó, os quais são altamente hidrofílicos e contribuem fortemente para a absorção de umidade.

Para serem práticos, os pós utilizados como ingredientes para a indústria de alimentos devem proporcionar uma boa solubilidade. Solubilidade é a última etapa de dissolução de partículas e é considerado um fator decisivo para a qualidade destes produtos (JAYASUNDERA et al., 2011). A avaliação estatística dos dados de solubilidade mostrou haver diferença significativa para $o$ fator albumina e para a interação entre o fator albumina e o fator temperatura, em nível de $5 \%$ de probabilidade (Tabela 2). A solubilidade dos pós produzidos com adição de albumina foi aumentada em ambas as temperaturas estudadas (Figura 6). O efeito do agente espumante no fator solubilidade também foi estudado por Wang et al. (2000) no qual verificaram que o aumento das proporções de soja (0 a $50 \%$ ) nos extratos hidrossolúveis desidratados resultaram em um aumento da solubilidade destes produtos em água. Os valores encontrados para solubilidade foram variaram entre 3,2 e $4,0 \mathrm{~g}$ de amostra solúvel/100 mL de solução. 
Figura 6. Valores médios de higroscopicidade e solubilidade para os tratamentos estudados.
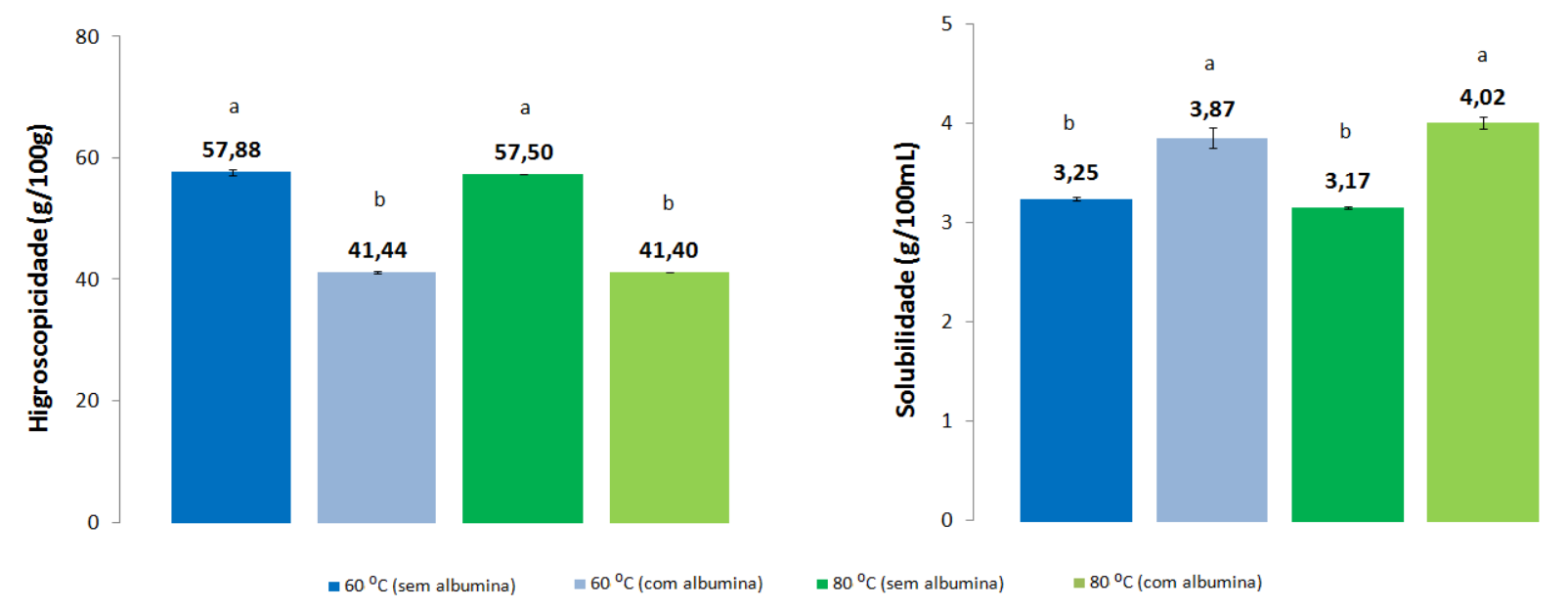

${ }^{\mathrm{a}-\mathrm{c}}$ médias médias seguidas por letras diferentes na mesma coluna diferem entre si $(\mathrm{p}<0,05)$.

Fonte: Elaboração dos autores.

\section{Conclusões}

A secagem em camada de espuma pode contribuir para a ocorrência de uma perda de umidade mais rápida durante este processo, no entanto, pode acelerar a perda de componentes sensíveis ao oxigênio, como o ácido ascórbico. A presença de albumina na formulação contribuiu para a produção de um material em pó com menor acidez e maior $\mathrm{pH}$. Apesar do teor de ácido ascórbico ter sido reduzido nos pós secos submetidos à formação de espuma, $\mathrm{o}$ uso do agentes espumante favoreceu a produção de pós com menor higroscopicidade, maior solubilidade e menores densidades, características importantes na reconstituição dos materiais desidratados.

\section{Referências}

ADOLFO LUTZ. Métodos fisico-químicos para análise de alimentos. 4. ed. Brasília, Ministério da Saúde, 2005. $1018 \mathrm{p}$.

ALVES, J. A.; VILAS BOAS, E. V. B.; VILAS BOAS, B. M.; SOUZA, E. C. Qualidade de produto minimamente processado à base de abóbora, cenoura, chuchu e mandioquinha-salsa. Ciência e Tecnologia de Alimentos, Campinas, v. 30, n. 3, p. 625-634, 2010.
BERISTAIN, C. I.; AZUARA, E.; VERNON-CARTER, E. J. Effect of water activity on the stability to oxidation of spray dried encapsulated orange peel oil using mesquite gum as wall material. Journal of Food Science, Chicago, v. 67, n. 1, p. 206-211, 2002.

BHANDARI, B. R.; DUMOULIN, H. M. J.; RICHARD, H. M. J.; NOLEAU, I.; LEBERT, A. M. Flavor encapsulation by spray drying: application to citral and linalyl acetate. Journal of Food Science, Chicago, v. 57, n. 1, p. 217-221, 1992.

BHANDARI, B. R.; HARTEL, R. W. Phase transitions during food powder production and powder stability. In: ONWULATA, C. (Ed.). Encapsulated and powdered foods. New York: Taylor \& Francis, 2005. p. 261-292.

BOTREL, D. A.; BORGES, S. V.; FERNANDES, R. V. B.; VIANA, A. D.; COSTA, J. M. G.; MARQUES, G. R. Evaluation of spray drying conditions on properties of microencapsulated oregano essential oil. International Journal of Food Science and Technology, Oxford, v. 47, n. 11, p. 2289-2296, 2012.

CAI, Y. Z.; CORKE, H. Production and properties of spray-dried Amaranthus betacyanin pigments. Journal of Food Science, Chicago, v. 65, n. 7, p. 1248-1252, 2000.

CASA, J.; EVANGELISTA, R. M. Influência das épocas de colheita na qualidade de tomate cultivado em sistemas alternativas. Semina: Ciências Agrárias, Londrina, v. 30, p. 1101-1108, 2009. Suplemento 1.

CHITARRA, M. I. F.; CHITARRA, A. B. Pós-colheita de frutos e hortaliças. Lavras: Editora UFLA, 2005. 785 p. 
COELHO, K. D.; PINTO, L. A. A. Caracterização da secagem convectiva de tomate (Lycopersicon esculentum Mill) em camada delgada. Vetor, Rio Grande, v. 21, n. 2, p. 5-21, 2011.

CORREIA, L. F. M.; FARAONI, A. S.; PINHEIROSANT'ANA, H. M. Efeitos do processamento industrial de alimentos sobre a estabilidade de vitaminas. Alimentos e Nutrição, Araraquara, v. 19, n. 1, p. 83-95, 2008.

CRUZ, P. M. F.; BRAGA, G. C.; GRANDI, A. M. Composição química, cor e qualidade sensorial de tomate seco a diferentes temperaturas. Semina: Ciências Agrárias, Londrina, v. 33, n. 4, p. 1475-1486, 2012.

CUNNINGHAM, S. E.; MCMINN, W. A. M.; MAGEE, T. R. A.; RICHARDSON, P. S. Effect of processing conditions on the water absorption and texture kinetics of potato. Journal of Food Engineering, Essex, v. 84, n. 2, p. 214-223, 2008.

FALADE, K. O.; ADEYANJU, K. I.; UZO-PETERS, P. I. Foam-mat drying of cowpea (Vigna unguiculata) using glyceryl monostearate and egg albumin as foaming agents. European Food Research and Technology, Berlin, v. 217, n. 6 , p. 486-491, 2003.

FERNANDES, R. V. B.; BORGES, S. V.; BOTREL, D. A. Influence of spray drying operating conditions on microencapsulated rosemary essential oil properties. Ciência e Tecnologia de Alimentos, Campinas, v. 33, p. 171-178, 2013. Suplemento 1.

FERNANDES, R. V. B.; BORGES, S. V.; BOTREL, D. A.; SILVA, E. K.; COSTA, J. M. G.; QUEIROZ, F Microencapsulation of rosemary essential oil: characterization of particles. Drying Technology, New York, v. 31, n. 11, p. 1245-1254, 2013 b.

FERNANDES, R. V. B.; QUEIROZ, F.; BOTREL, D. A.; ROCHA, V. V.; LIMA, C. F.; SOUZA, V. R. Foam mat drying of tomato pulp. Bioscience Journal, Uberlândia, v. 29 , n. 4 , p. $816-825,2013$ a.

FILGUEIRA, F. A. R. Manual de olericultura: agrotecnologia moderna na produção e comercialização de hortaliças. Viçosa: UFV, 2003. 412 p.

FINNEY, J.; BUFFO, R.; REINECCIUS, G. A. Effects of type of atomization and processing temperatures on the physical properties and stability of spray-dried flavors. Journal of Food Science, Chicago, v. 67, n. 3, p. 11081114, 2002.

GARCIA, R.; LEAL, F.; ROLZ, C. Drying of bananas using microwave and air ovens. International Journal of Food Science and Technology, Misore, v. 23, n. 1, p. 7380, 1988.
GENIN, N.; RENÉ, F. Analyse du rôle de la transition vitreuse dans les procédés de conservation agroalimentaires. Journal of Food Engineering, Essex, v. 26, n. 4, p. 391-408, 1995.

GIOVANELLI, G.; PARADISO, A. Stability of dried and intermediate moisture tomato pulp during storage. Journal of Agricultural and Food Chemistry, Washington, v. 50, n. 25, p. 7277-7281, 2002.

JAYASUNDERA, M.; ADHIKARI, B.; HOWES, T.; ALDRED, P. Surface protein coverage and its implications on spray-drying of model sugar-rich foods: solubility, powder production and characterization. Food Chemistry, Reading, v. 128, n. 4, p. 1003-1016, 2011.

KADAM, D. M.; LATA, D. V. K. S.; PANDEY, A. $\mathrm{K}$. Influence of different treatments on dehydrated cauliflower quality. International Journal of Food Science and Technology, Misore, v. 40, n. 8, p. 849-856, 2005.

KADAM, D. M.; NANGARE, D. M.; OBEROI, H. S. Influence of pre- treatment on microbial load of stored dehydrated onion slices. International Journal of Food Science and Technology, Misore, v. 44, n. 10, p. 19021908, 2009.

KADAM, D. M.; WILSON, R. A.; MANISHA, K. S. Influence of foam mat drying on quality of tomato powder. International Journal of Food Properties, Philadelphia, v. 15, n. 1, p. 211-220, 2012.

KUDRA, T.; MUJUMDAR, A. S. Advanced drying technologies. New York: Marcel Dekker, Inc., 2001. 472 p.

MARTINAZZO, A. P.; MELO, E. C.; CORRÊA, P. C.; SANTOS, R. H. S. Modelagem matemática e parâmetros qualitativos da secagem de folhas de capim-limão [Cymbopogon citratus (DC.) Stapf]. Revista Brasileira de Plantas Medicinais, Botucatu, v. 12, n. 4, p. 488-498, 2010.

MAYOR, L.; SERENO, A. M. Modelling shrinkage during convective drying of food materials: a review. Journal of Food Engineering, Essex, v. 61, n. 3, p. 373386, 2004.

MEHTA, M. B.; MEHTA, B.; BAPODRA, A. H.; JOSHI, H. D. Effect of germination and heat processing on protein, riboflavin, vit-C and niacin content in peas, cowpea, red gram and wheat. Asian Journal of Home Science, Muzaffarnagar, v. 2, n. 1-2, p. 34-38, 2007.

NETTO, F. M.; DESOBRY, S. A.; LABUZA, T. P. Effect of water content on the glass transition, caking and stickiness of protein hydrolysates. International Journal of Food Properties, Philadelphia, v. 1, n. 2, p. 141-161, 1998. 
RATTI, C.; KUDRA, T. Drying of foamed biological materials: opportunities and challenges. Drying Technology, New York, v. 24, n. 9, p. 1101-1108, 2006.

ROOS, Y. H. Importance of glass transition and water activity to spray drying and stability of dairy powders. Lait, Rennes, v. 82, n. 4, p. 475-484, 2002.

SANKAT, C. K.; CASTAIGNE, F. Foaming and drying behaviour of ripe bananas. LWT - Food Science and Technology, Oxford, v. 37, n. 5, p. 517-525, 2004.

SILVA, A. S.; GURJÃO, K. C. O.; ALMEIDA, F. A. C.; BRUNO, R. L. A.; PEREIRA, W. E. Desidratação da polpa de tamarindo pelo método de camada de espuma. Ciência e Agrotecnologia, Lavras, v. 32, n. 6, p. 18991905, 2008.
THUWAPANICHAYANAN,

PRACHAYAWARAKORN, S.; SOPONRONNARIT, S. Effects of foaming agents and foam density on drying characteristics and textural property of banana foams. LWT - Food Science and Technology, Oxford, v. 47, n. 2, p. 348-357, 2012.

TRUONG, V.; BHANDARI, B. R.; HOWES, T. Optimisation of co-current spray drying process of sugarrich foods. Part II-optimisation of spray drying process based on glass transition temperature. Journal of Food Engineering, Essex, v. 71, n. 1, p. 66-72, 2005.

WANG, S. H.; FERNANDES, S. M.; CABRAL, L. C.; ARAUJO, F. B. Absorção de gordura, solubilidade e propriedades espumantes dos extratos hidrossolúveis desidratados de arroz e soja. Ciência e Tecnologia de Alimentos, Campinas, v. 20, n. 2, p. 187-191, 2000. 